\title{
Evaluation of effectiveness for using of Electronic Health Information System at Al-Rajhy Assiut
} University Hospital for Liver

\author{
Samia Khalaf Mohamed, Hala Ramzy Youssef ${ }^{2}$, Soad Ahmed Ghallab ${ }^{3}$, Sanaa Mohamed Aref ${ }^{4}$ \\ ${ }^{2}$ Professor of Nursing Administration, Faculty of Nursing Assuit University, \\ ${ }^{3}$ Professor of Nursing Administration, Faculty of Nursing Assuit University \\ ${ }^{4}$ Assist Professor of Nursing Administration, Faculty of Nursing-Minia University,
}

\begin{abstract}
Background: Electronic Health Information System (EHIS) are currently considered a major part of the healthcare system; this importance emerges from the importance of their role in managing all patient data to documenting all medical services. Aim to evaluate the effectiveness of health care providers' usage of Electronic Health Record at AlRajhy Assiut University Hospital for Liver. Research design; Descriptive comparative research design was used for this study. Setting; the study had been conducted- at Al-Rajhy Assiut University Hospital for Liver. Subjects; the study subject included all users of the EHRs, $(n=250)$ Tools; one tool consists of three parts as following; personal and professional characteristics data sheet, Evaluation of electronic health records sheet, and Utility of electronic hospital information system sheet. Results; the study finding revealed that the majority of studied subjects were agreed that the system works well, easy to input information into electronic records, and easy to use, most of them agreed that the system provides clear, useful, complete information, provides reliable information, records are useful, present updated information in an appropriate format. And more than half of them agreed that the records offer reliability, and moreover facilitates coordination of tasks, decision process, auditing and release of procedures, facilitates analysis of hospital bills, verification of the materials \& medications used in units, and facilitates hospital billing. Conclusion; There were high statistical significant difference among physicians, nurses, and employees' regarding to evaluation of electronic records system. There were statistical significant differences among physicians, nurses, and employees and general utility of electronic records. Recommendation; guideline and manual book about how to use of Health Information System should be available for users to support them in documentations. Arrange a training program to assess awareness for HIS users regarding the benefits of Information Technology and HIS. Training should be assured by arranging workshops to improve their computer and HIS proficiency.

Keywords: Evaluation, Electronic Health Information System, Effectiveness.
\end{abstract}

\section{Introduction}

Hospital Information System (HIS) is comprehensive software for patient's information integration for transfer and exchange comprehensive patient's information between wards to accelerate process of patient care, improve quality, raise satisfaction and reduce costs. Electronic Hospital Information Systems (e-HISs) are "computer systems that collect, store, process, retrieve, display, and communicate timely information needed in practice, education, administration and research (Aghazadeh, et al, 2013)

Electronic health record (EHRs) consider as a part of (e-HIS) systems that can enable hospitals to store and retrieve complete patient information to be used by health care providers, and sometimes patients, during a patient's hospitalization, over time, and across care settings. Any health care system must depend on a well formed information system to achieve a successful management. Data are the center of all decision making in health care. So the data should be reliable, complete and well-structured to make the computers assist in fulfilling these requirements (Shortliffe et al., 2014).

Moreover, EHRs has many benefits as: reduce errors, increase speed of care, accuracy and also lower health costs by coordinating services and improving quality of care while traditional paper based medical records are bulky and harder to maintain, so these problems can be easily solved by implementing e-HIS (Jha et al., 2018).

However, the target of EHRs involves increased efficiencies, improved accuracy, timeliness, availability, and productivity. Clinicians in environments with EHRs spend less time updating static data, such as demographic and health history, because these data are populated throughout the record and generally remain constant. Clinicians also have better access to other automated information, improved $P$ a g e | 107 organization tools, and alert screens. Alerts are a significant capacity of EHRs because they identify medication allergies and other needed notices (Department of Health \& Human Services, 2014).

Furthermore, EHRs can help the nurse to monitor the usage of drugs effectively which leads to better utilization of medicines and better cost control. Also, provide facilitation of the information sharing, mass archives, security, high reliability, standardization of work processes in the hospital, improving the patient care through standardization of performance and support of medical information format of images, and figures (Rose et al., 2014).

Electronic documentation systems improve the worth of EHRs by providing electronic release of clinical notes; patient assessments; and clinical reports, such as medication administration records. Examples of clinical documentation that include: physician, nurse, and other clinician notes, flow sheets (vital signs, input and output, problem lists), per-operative notes, discharge summaries, consents (procedural) and medical record (Coffman et al., 2012).

In other words, EHR is principally focused on the patient, as well as on medical and nursing care, and the administrative issues needed to support these kinds of care. Therefore, EHR frees the medical staff from data management tasks so that they can concentrate more on patient care improved efficiency: Also they will never have to face adversities such as missing records, delays, duplicate records and the data is to be well-organized (Khalifa, 2014).

Nursing Information System (NIS) is "a part of health care information system that deals with nursing aspects, particularly the maintenance of the nursing record". Nursing Record System is the record of care planned given to Samia Kh., et al 
individual patients by qualified nurses or other caregivers, to assess patient acuity, prepare a plan of care, and document care. Nursing information systems help nurses plan support activities, and communicate with related services (Cohen, 2016).

The main utility for EHRs it provides a platform which electronic media are used to facilitate and enhance quality assurance of the public consumers' healthcare service delivery. Moreover, the systems support new methods to create, keep and maintain records for hospitals as well as improve management, accountability and security in processes, improve the handling of information by healthcare providers (Middleton, et al; 2013).

\section{Significance of the study}

Introduction of e-HIS considered initiatives to transform existing paper-based systems in most teaching healthcare institutions in developing countries has usually been a difficult process of change, often faces with several challenges and problems such as lack of adequate resources (poor financial resources) and poor infrastructural development, inadequate skills and knowledge at a local level to handle new systems and technologies. The success of the system is achieved through user acceptance with the system (Ojo and Popoola, 2015).

Al-Rajhy University Hospital has a fully automated e-HIS since its opening in (2012). The implementation of eHIS to a hospital is consider a new system in Assuit University Hospitals as a whole, in an attempts to convert the paper-based health record system to a fully automated electronic record systems which is very problematic for nurses and some employees and faced with resistance at the beginning and hospital administration overcome this resistance by providing support and training for all health care providers involved in the system of e-HIS. It was felt necessary to evaluate to what extent the e-HIS was effective.

\section{Aims of the study}

The aim of the current study was to evaluate the effectiveness of using EHRs at Al-Rajhy Assiut University Hospital for Liver.

\section{Research Question}

Does the usage of electronic health records are effective for health care providers?

\section{Subjects \& Method}

\section{Study Design}

the present study.

Descriptive comparative research design was used in

\section{Study Setting}

The present study carried out - at Al-Rajhy Assiut University Hospital for Liver at the following units: general ward, intensive care unit, critical care unit, endoscopic unit, operating room, outpatient clinics, laboratory, and X- ray.

\section{Study Subjects}

The study subjects included all users of the e-HIS, $(n=250)$ categorized as follows; physicians $(n=20)$, staff nurses $(n=200)$, and employees $(n=30)$ from admission office, human resources personnel, and financial department.

\section{Tool of data collection}

One tool was used to collect data through selfadministered questionnaire consists of three parts.

\section{Part (1): Personal and characteristics data sheet.}

Designed to collect data about study participants personal characteristics as; age, gender, marital status, educational qualification, current job title, years of experience, duration of using electronic records system by each categories in hospital.

\section{Part (2): Evaluation of electronic health records scale.}

It developed by Cortes, (2008) and consists of 23 items comprised of 4 main domains; general evaluation of operation of the electronic system (6 items), evaluation of the information made available by electronic system ( 5 items), and evaluation of the screens of the system ( 5 items). And general evaluation of electronic records ( 7 items).Asking respondents to indicate their agreement or disagreement with the statement measured on five point likertscale;(1)Completely disagree, (2) disagree, (3) indifferent, (4) agree, and (5) completely agree.

\section{Part (3): Utility of electronic hospital information system scale.}

It was developed by Cortes (2008) it consists of 20 items comprised 3 main domains as follows; utility of electronic records ( 6 items), utility of the electronic system for medical and nursing work ( 8 items). And utility of the electronic system for the processes of billing and auditing ( 6 items). Asking respondents to indicate agreement or disagreement with the statement measured on a five point likert- scale; (1) completely disagree, (2) disagree, (3) indifferent, (4) agree, and (5) completely agree.

\section{Scoring system:}

The scores of the items were summed-up and divided by the number of items, giving the mean score. These scores were converted into a percent. Then the mean and standard deviations of the scores were computed. If the mean scores percent of responses were $\geq 60 \%$ means high level but if $\leq$ $60 \%$ means low level.

\section{Administration design}

An official permission had been obtained from the medical director of Rajhy hospital to collect the necessary data from all users of hospital information system; also oral agreement permission was obtained from all users of EHIS to participate in the study.

\section{Validity and reliability}

To achieve the criteria of trustworthiness of the tools of data collection in this study, validity of tool were revised and validated for their face validity by five experts in the field of study. They were three assistant professors of Nursing Administration - Faculty of Nursing - Assuit University and one lecturer of Nursing Administration - Faculty of Nursing Minia University, and one professor of IT unit-Faculty of Information Technology- Assuit University. Accordingly the modifications required already done by the researcher.

The reliability of the data collection tools was assessed through measuring their internal consistency by Cronbach Alpha Coefficient test, and it was proven test (0.832). 


\section{Pilot study:}

A pilot was done to investigate and ensure the feasibility, applicability, clarity and reliability of the study tools. The pilot study included $10 \%$ of total number as follows ( 2 physicians, 3 employees, and 20 staff nurses) and the necessary modifications were done.

\section{Ethical Considerations}

Approvals were taken from Ethical Committee of Faculty of Nursing of Minia University, The purpose of this study was explained to all participants and oral consent taken from the participants in the present study, and Confidentiality of data, voluntary participation and right to refuse to participate in the study was emphasized to subjects.

\section{Operational design}

This phase took about 3 months from January to March 2018 for reviewing the available literatures concerning the topic of the study; translation of the study tools from
English to Arabic was done. Accordingly, modifications were done and the final form was developed. This phase took about 2 month from April to May 2018.

\section{Data collection phase:}

The data collected through self- administered questionnaire from participants for collection necessary data, this took about 15 minutes for each participant. The whole duration for data collection took about 4 months from May to August 2018.

\section{Statistical design:}

The data were reviewed, prepared for computer entry, coded, analyzed and tabulated. Descriptive statistics (i.e., frequencies, percentage, mean and standard deviation etc.) was done using computer program SPSS version 11. ANOVA test, used to compare differences in the distribution of frequencies among different groups. It is considered * significant when $\mathrm{P}$ - value were less than 0.05 or $(\mathrm{P}<0.05)$.

\section{Results}

Table (1): Percentage distribution of personal characteristics of studied subjects $(n=250)$

\begin{tabular}{|c|c|c|c|c|c|c|}
\hline \multirow{3}{*}{ Items } & \multicolumn{6}{|c|}{ Occupation } \\
\hline & \multicolumn{2}{|c|}{$\begin{array}{c}\text { Physicians } \\
(\mathrm{n}=20)\end{array}$} & \multicolumn{2}{|c|}{$\begin{array}{c}\text { Nurses } \\
(n=200)\end{array}$} & \multicolumn{2}{|c|}{$\begin{array}{c}\text { Employees } \\
(\mathbf{n}=\mathbf{3 0})\end{array}$} \\
\hline & No. & $\%$ & No. & $\%$ & No. & $\%$ \\
\hline \multicolumn{7}{|l|}{ Age: (years) } \\
\hline$<25$ & 0 & 0.0 & 79 & 39.5 & 0 & 0.0 \\
\hline $25-30$ & 12 & 60.0 & 78 & 39.0 & 6 & 20.0 \\
\hline$>30$ & 8 & 40.0 & 43 & 21.5 & 24 & 80.0 \\
\hline Mean \pm SD & \multicolumn{2}{|c|}{$30.25 \pm 3.49$} & \multicolumn{2}{|c|}{$27.11 \pm 6.22$} & \multicolumn{2}{|c|}{$36.37 \pm 6.38$} \\
\hline \multicolumn{7}{|l|}{ Gender: } \\
\hline Male & 12 & 60.0 & 9 & 4.5 & 22 & 73.3 \\
\hline Female & 8 & 40.0 & 191 & 95.5 & 8 & 26.7 \\
\hline \multicolumn{7}{|l|}{ Marital status: } \\
\hline Married & 12 & 60.0 & 138 & 69.0 & 27 & 90.0 \\
\hline Not married & 8 & 40.0 & 62 & 31.0 & 3 & 10.0 \\
\hline \multicolumn{7}{|l|}{ Years of experience: } \\
\hline$<5$ & 1 & 5.0 & 49 & 24.5 & 0 & 0.0 \\
\hline $5-10$ & 13 & 65.0 & 100 & 50.0 & 6 & 20.0 \\
\hline$>10$ & 6 & 30.0 & 51 & 25.5 & 24 & 80.0 \\
\hline Mean \pm SD & \multicolumn{2}{|c|}{$9.25 \pm 3.49$} & \multicolumn{2}{|c|}{$8.76 \pm 6.05$} & \multicolumn{2}{|c|}{$15.20 \pm 4.29$} \\
\hline \multicolumn{7}{|c|}{ Duration of electronic system use in hospital: } \\
\hline$<2$ & 7 & 35.0 & 26 & 13.0 & 0 & 0.0 \\
\hline $2-4$ & 11 & 55.0 & 119 & 59.5 & 10 & 33.3 \\
\hline$>4$ & 2 & 10.0 & 55 & 27.5 & 20 & 66.7 \\
\hline \multicolumn{7}{|l|}{ Educational level: } \\
\hline Technical secondary school & 0 & 0.0 & 53 & 26.5 & 1 & 3.3 \\
\hline Technical institute & 0 & 0.0 & 121 & 60.5 & 9 & 30.0 \\
\hline Bachelor or higher & 20 & 100.0 & 26 & 13.0 & 20 & 66.7 \\
\hline
\end{tabular}

Personal data of studied subjects (physicians, nurses, and employees) depicted at table (1). Regarding to physicians nearly two thirds of physicians $\mathbf{( 6 0 \% )}$ ) was male, married. Their mean age was (30.25) years old, while the mean year of experience was (9.25) and duration of electronic system used in hospital from 2-4 years. Regards to the nurses, the majority of them were female, married and graduated from technical institute, $(\mathbf{9 5 . 5} \%, \mathbf{6 9 . 0} \%$ and $\mathbf{6 0 . 5} \%)$ respectively. Their mean age was $(\mathbf{2 7 . 1 1 )}$ years old, while

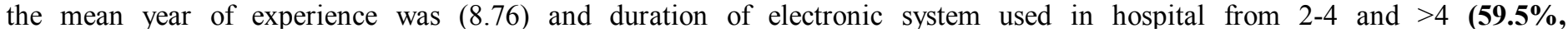
$\mathbf{2 7 . 5 \% ) . R e g a r d i n g ~ t o ~ e m p l o y e e s , ~ t h e ~ h i g h e s t ~ p e r c e n t ~ o f ~ t h e m ~ w e r e ~ m a r r i e d , ~ m a l e , ~ a n d ~ h a d ~ b a c h e l o r ~ d e g r e e ~ o r ~ h i g h e r ~} \mathbf{( 9 0 . 0 \% \text { , }}$ $\mathbf{7 3 . 3 \%}$ ) and $(\mathbf{6 6 . 7 \%})$ respectively. Their mean age was $\mathbf{( 3 6 . 3 7 )}$, the mean years of experience was (15.20) and duration of electronic system used in hospital more than 4 years.

Table (2): Percentage distribution of physicians evaluation of electronic records system used in AL-Rajhy hospital (n=20)

\begin{tabular}{|c|c|c|c|c|c|c|c|c|c|c|}
\hline \multirow[t]{2}{*}{ Items } & \multicolumn{2}{|c|}{$\begin{array}{c}\text { Completely } \\
\text { agree }\end{array}$} & \multicolumn{2}{|c|}{ Agree } & \multicolumn{2}{|c|}{ Indifferent } & \multicolumn{2}{|c|}{ Disagree } & \multicolumn{2}{|c|}{$\begin{array}{c}\text { Completely } \\
\text { disagree }\end{array}$} \\
\hline & No. & $\%$ & No. & $\%$ & No. & $\%$ & No. & $\%$ & No. & $\%$ \\
\hline \multicolumn{11}{|c|}{ A-General evaluation of electronic system operation: } \\
\hline 1-It is easy to use & 18 & 90.0 & 2 & 10.0 & 0 & 0.0 & 0 & 0.0 & 0 & 0.0 \\
\hline 2-The system works well & 19 & 95.0 & 1 & 5.0 & 0 & 0.0 & 0 & 0.0 & 0 & 0.0 \\
\hline 3-The systems' speed is good & 19 & 95.0 & 1 & 5.0 & 0 & 0.0 & 0 & 0.0 & 0 & 0.0 \\
\hline 4-The system has few interruption & 6 & 30.0 & 12 & 60.0 & 0 & 0.0 & 2 & 10.0 & 0 & 0.0 \\
\hline
\end{tabular}


Minia Scientific Nursing Journal (Print) (ISSN 2537-012X) Vol. (6) No. (1) December 2019

\begin{tabular}{|c|c|c|c|c|c|c|c|c|c|c|}
\hline \multirow[t]{2}{*}{ Items } & \multicolumn{2}{|c|}{$\begin{array}{c}\text { Completely } \\
\text { agree }\end{array}$} & \multicolumn{2}{|c|}{ Agree } & \multicolumn{2}{|c|}{ Indifferent } & \multicolumn{2}{|c|}{ Disagree } & \multicolumn{2}{|c|}{$\begin{array}{c}\text { Completely } \\
\text { disagree }\end{array}$} \\
\hline & No. & $\%$ & No. & $\%$ & No. & $\%$ & No. & $\%$ & No. & $\%$ \\
\hline 5-It is easy to input information into the electronic record & 19 & 95.0 & 1 & 5.0 & 0 & 0.0 & 0 & 0.0 & 0 & 0.0 \\
\hline 6-It facilitates the implementation of internal protocol & 12 & 60.0 & 8 & 40.0 & 0 & 0.0 & 0 & 0.0 & 0 & 0.0 \\
\hline \multicolumn{11}{|c|}{ B-Evaluation of the information made available: } \\
\hline 1-The information is divided in a consistent manner & 12 & 60.0 & 7 & 35.0 & 0 & 0.0 & 1 & 5.0 & 0 & 0.0 \\
\hline 2-The system provides clear information & 19 & 95.0 & 1 & 5.0 & 0 & 0.0 & 0 & 0.0 & 0 & 0.0 \\
\hline 3-The system provides reliable information & 14 & 70.0 & 6 & 30.0 & 0 & 0.0 & 0 & 0.0 & 0 & 0.0 \\
\hline 4-The system provides useful information & 17 & 85.0 & 3 & 15.0 & 0 & 0.0 & 0 & 0.0 & 0 & 0.0 \\
\hline 5-The system provides complete information & 14 & 70.0 & 6 & 30.0 & 0 & 0.0 & 0 & 0.0 & 0 & 0.0 \\
\hline \multicolumn{11}{|c|}{ C-Evaluation of the screens of the system: } \\
\hline 1-Easy access to the records & 14 & 70.0 & 6 & 30.0 & 0 & 0.0 & 0 & 0.0 & 0 & 0.0 \\
\hline 2-Disappearance of paper records & 9 & 45.0 & 10 & 50.0 & 1 & 5.0 & 0 & 0.0 & 0 & 0.0 \\
\hline 3-Ability to see and analyze the patient data as a whole & 15 & 75.0 & 5 & 25.0 & 0 & 0.0 & 0 & 0.0 & 0 & 0.0 \\
\hline $\begin{array}{l}\text { 4-Ability to retrieve faster and reliable data for scientific } \\
\text { research }\end{array}$ & 17 & 85.0 & 3 & 15.0 & 0 & 0.0 & 0 & 0.0 & 0 & 0.0 \\
\hline 5-Restructuring is possible for the necessities & 10 & 50.0 & 9 & 45.0 & 0 & 0.0 & 1 & 5.0 & 0 & 0.0 \\
\hline \multicolumn{11}{|c|}{ D-General evaluation of the electronic records system: } \\
\hline 1-The generation of records is fast & 16 & 80.0 & 4 & 20.0 & 0 & 0.0 & 0 & 0.0 & 0 & 0.0 \\
\hline 2-The records are useful & 17 & 85.0 & 3 & 15.0 & 0 & 0.0 & 0 & 0.0 & 0 & 0.0 \\
\hline 3-The records present updated information & 17 & 85.0 & 3 & 15.0 & 0 & 0.0 & 0 & 0.0 & 0 & 0.0 \\
\hline 4-The records are easily configured & 17 & 85.0 & 3 & 15.0 & 0 & 0.0 & 0 & 0.0 & 0 & 0.0 \\
\hline 5-The records of the system present an appropriate format & 17 & 85.0 & 3 & 15.0 & 0 & 0.0 & 0 & 0.0 & 0 & 0.0 \\
\hline 6-The records of the system present good organization & 16 & 80.0 & 4 & 20.0 & 0 & 0.0 & 0 & 0.0 & 0 & 0.0 \\
\hline 7-The system has enough records for its activity & 15 & 75.0 & 5 & 25.0 & 0 & 0.0 & 0 & 0.0 & 0 & 0.0 \\
\hline
\end{tabular}

Table (2) describes physicians evaluation of electronic records system usage; regarding to general evaluation of electronic health records operation; the vast majority of physicians(95\%) completely agreed that the system works well, speed is good, it is easy to input information into electronic records and(90\%) agreed that the records easy to use. While about two thirds of them agreed that it facilitates the implementation of internal protocol. Regarding to evaluation of information made available, majority of them completely agreed that the system provides clear, useful, complete, and provides reliable information $(\mathbf{9 5 \%}, \mathbf{8 5} \%$,and $\mathbf{7 0 \%}$ ) respectively. Regarding to evaluation of the screens of the system, more than two thirds of them completely agreed that the screens has the ability to retrieve faster and reliable data for specific research, has the ability to see \& analyze the patient data as a whole and easy access to the records $(\mathbf{8 5 \%}, \mathbf{7 5 \%}$, and $\mathbf{7 0 \%}$ ) respectively. For general evaluation of electronic records system, the majority of physicians $\mathbf{( 8 5 \%}$ ) completely agreed that the records are useful, present updated information, in an appropriate format, and are easily configured, while $\mathbf{( 7 5 \% )}$ )of them agreed on the system has enough records for its activity.

Table (3): Percentage distribution of nurse's evaluation of electronic records system used in AL-Rajhy hospital (n=200)

\begin{tabular}{|c|c|c|c|c|c|c|c|c|c|c|}
\hline \multirow[t]{2}{*}{ Items } & \multicolumn{2}{|c|}{$\begin{array}{c}\text { Completely } \\
\text { agree }\end{array}$} & \multicolumn{2}{|c|}{ Agree } & \multicolumn{2}{|c|}{ Indifferent } & \multicolumn{2}{|c|}{ Disagree } & \multicolumn{2}{|c|}{$\begin{array}{c}\text { Completely } \\
\text { disagree }\end{array}$} \\
\hline & No. & $\%$ & No. & $\%$ & No. & $\%$ & No. & $\%$ & No. & $\%$ \\
\hline \multicolumn{11}{|c|}{ A-General evaluation of electronic system operation: } \\
\hline 1- It is easy to use & 92 & 46.0 & 92 & 46.0 & 5 & 2.5 & 11 & 5.5 & 0 & 0.0 \\
\hline 2-The system works well & 79 & 39.5 & 109 & $\mathbf{5 4 . 5}$ & 10 & 5.0 & 2 & 1.0 & 0 & 0.0 \\
\hline 3-The systems' speed is good & 75 & 37.5 & 97 & 48.5 & 23 & 11.5 & 5 & 2.5 & 0 & 0.0 \\
\hline 4-The system has few interruption & 52 & 26.0 & 110 & $\mathbf{5 5 . 0}$ & 29 & 14.5 & 9 & 4.5 & 0 & 0.0 \\
\hline 5-It is easy to input information into the electronic record & 76 & 38.0 & 116 & 58.0 & 2 & 1.0 & 6 & 3.0 & 0 & 0.0 \\
\hline 6-It facilitates the implementation of internal protocol & 59 & 29.5 & 94 & 47.0 & 38 & 19.0 & 9 & 4.5 & 0 & 0.0 \\
\hline \multicolumn{11}{|c|}{ B-Evaluation of the information made available: } \\
\hline 1-The information is divided in a consistent manner & 55 & 27.5 & 106 & 53.0 & 33 & 16.5 & 6 & 3.0 & 0 & 0.0 \\
\hline 2-The system provides clear information & 84 & 42.0 & 112 & 56.0 & 4 & 2.0 & 0 & 0.0 & 0 & 0.0 \\
\hline 3-The system provides reliable information & 61 & 30.5 & 91 & 45.5 & 41 & 20.5 & 7 & 3.5 & 0 & 0.0 \\
\hline 4-The system provides useful information & 78 & 39.0 & 112 & 56.0 & 7 & 3.5 & 3 & 1.5 & 0 & 0.0 \\
\hline 5-The system provides complete information & 61 & 30.5 & 93 & 46.5 & 28 & 14.0 & 18 & 9.0 & 0 & 0.0 \\
\hline \multicolumn{11}{|c|}{ C-Evaluation of the screens of the system: } \\
\hline 1-Easy access to the records & 109 & 54.5 & 90 & 45.0 & 1 & 0.5 & 0 & 0.0 & 0 & 0.0 \\
\hline 2-Disappearance of paper records & 65 & 32.5 & 98 & 49.0 & 19 & 9.5 & 12 & 6.0 & 6 & 3.0 \\
\hline 3-Ability to see and analyze the patient data as a whole & 88 & 44.0 & 108 & 54.0 & 2 & 1.0 & 2 & 1.0 & 0 & 0.0 \\
\hline $\begin{array}{l}\text { 4-Ability to retrieve faster and reliable data for scientific } \\
\text { research }\end{array}$ & 54 & 27.0 & 118 & 59.0 & 23 & 11.5 & 5 & 2.5 & 0 & 0.0 \\
\hline 5-Restructuring is possible for the necessities & 42 & 21.0 & 113 & 56.5 & 40 & 20.0 & 5 & 2.5 & 0 & 0.0 \\
\hline \multicolumn{11}{|c|}{ D-General evaluation of the electronic records system: } \\
\hline 1-The generation of records is fast & 110 & $\mathbf{5 5 . 0}$ & 88 & 44.0 & 1 & 0.5 & 1 & 0.5 & 0 & 0.0 \\
\hline 2-The records are useful & 106 & $\mathbf{5 3 . 0}$ & 92 & 46.0 & 1 & 0.5 & 1 & 0.5 & 0 & 0.0 \\
\hline 3-The records present updated information & 108 & $\mathbf{5 4 . 0}$ & 90 & 45.0 & 2 & 1.0 & 0 & 0.0 & 0 & 0.0 \\
\hline 4-The records are easily configured & 101 & 50.5 & 89 & 44.5 & 9 & 4.5 & 1 & 0.5 & 0 & 0.0 \\
\hline 5-The records of the system present an appropriate format & 98 & 49.0 & 96 & 48.0 & 5 & 2.5 & 1 & 0.5 & 0 & 0.0 \\
\hline 6-The records of the system present good organization & 98 & 49.0 & 97 & 48.5 & 2 & 1.0 & 3 & 1.5 & 0 & 0.0 \\
\hline 7-The system has enough records for its activity & 87 & 43.5 & 96 & 48.0 & 12 & 6.0 & 5 & 2.5 & 0 & 0.0 \\
\hline
\end{tabular}

Nurses evaluation of electronic records system usage; Table (3): illustrated that more than half of them agreed that the system easy to input information into electronic records, has few interruption and works well (58\%, 55\%, and 54.5\%) respectively. 
For evaluation of information made available; (56\%) of nurses agreed that the system provides clear, useful information, (53\%) agreed that it divided in a consistent manner. While (46.5\%) agreed that the system provides complete information. Regarding to evaluation of the screens of system; more than half of nurses agreed that it has the ability to retrieve faster and reliable data for scientific research, restricting is possible for the necessities and has the ability to see $\&$ analyze the patient data as a whole $\mathbf{( 5 9 \%}$, $\mathbf{5 6 . 5 \%}$, and $\mathbf{5 4 \%}$ ) respectively. And $\mathbf{( 5 4 . 5 \% )}$ ) completely agreed that it is easy access to the records. For general evaluation of electronic records system; more than half of nurses completely agreed that the generation of records is fast, records present updated information and it are useful $(\mathbf{5 5 \%}, \mathbf{5 4 \%}$, and $\mathbf{5 3 \%})$ respectively. While nearly to half $\mathbf{( 4 9 \% )}$ ) agreed that it present an appropriate format and present good organization. And (43.5\%) agreed that it has enough records for its activity.

Table (4): Percentage distribution of employees evaluation of electronic records system used in AL-Rajhy hospital (n=30)

\begin{tabular}{|c|c|c|c|c|c|c|c|c|c|c|}
\hline \multirow[t]{2}{*}{ Items } & \multicolumn{2}{|c|}{$\begin{array}{l}\text { Completely } \\
\text { agree }\end{array}$} & \multicolumn{2}{|c|}{ Agree } & \multicolumn{2}{|c|}{ Indifferent } & \multicolumn{2}{|c|}{ Disagree } & \multicolumn{2}{|c|}{$\begin{array}{c}\text { Completely } \\
\text { disagree }\end{array}$} \\
\hline & No. & $\%$ & No. & $\%$ & No. & $\%$ & No. & $\%$ & No. & $\%$ \\
\hline \multicolumn{11}{|c|}{ A-General evaluation of electronic system operation: } \\
\hline 1-It is easy to use & 26 & 86.7 & 4 & 13.3 & 0 & 0.0 & 0 & 0.0 & 0 & 0.0 \\
\hline 2-The system works well & 24 & 80.0 & 5 & 16.7 & 1 & 3.3 & 0 & 0.0 & 0 & 0.0 \\
\hline 3-The systems' speed is good & 23 & 76.7 & 6 & 20.0 & 1 & 3.3 & 0 & 0.0 & 0 & 0.0 \\
\hline 4-The system has few interruption & 22 & 73.3 & 5 & 16.7 & 0 & 0.0 & 3 & 10.0 & 0 & 0.0 \\
\hline $\begin{array}{l}\text { 5-It is easy to input information into the electronic } \\
\text { record }\end{array}$ & 27 & 90.0 & 3 & 10.0 & 0 & 0.0 & 0 & 0.0 & 0 & 0.0 \\
\hline $\begin{array}{l}\text { 6-It facilitates the implementation of internal } \\
\text { protocol }\end{array}$ & 23 & 76.7 & 6 & 20.0 & 0 & 0.0 & 1 & 3.3 & 0 & 0.0 \\
\hline \multicolumn{11}{|c|}{ B-Evaluation of the information made available: } \\
\hline 1-The information is divided in a consistent manner & 24 & 80.0 & 3 & 10.0 & 3 & 10.0 & 0 & 0.0 & 0 & 0.0 \\
\hline 2-The system provides clear information & 25 & 83.3 & 5 & 16.7 & 0 & 0.0 & 0 & 0.0 & 0 & 0.0 \\
\hline 3-The system provides reliable information & 21 & 70.0 & 6 & 20.0 & 3 & 10.0 & 0 & 0.0 & 0 & 0.0 \\
\hline 4-The system provides useful information & 24 & 80.0 & 5 & 16.7 & 1 & 3.3 & 0 & 0.0 & 0 & 0.0 \\
\hline 5-The system provides complete information & 21 & 70.0 & 6 & 20.0 & 3 & 10.0 & 0 & 0.0 & 0 & 0.0 \\
\hline \multicolumn{11}{|c|}{ C-Evaluation of the screens of the system: } \\
\hline 1-Easy access to the records & 26 & 86.7 & 4 & 13.3 & 0 & 0.0 & 0 & 0.0 & 0 & 0.0 \\
\hline 2-Disappearance of paper records & 23 & 76.7 & 7 & 23.3 & 0 & 0.0 & 0 & 0.0 & 0 & 0.0 \\
\hline $\begin{array}{l}\text { 3-Ability to see and analyze the patient data as a } \\
\text { whole }\end{array}$ & 22 & 73.3 & 7 & 23.3 & 1 & 3.3 & 0 & 0.0 & 0 & 0.0 \\
\hline $\begin{array}{l}\text { 4-Ability to retrieve faster and reliable data for } \\
\text { scientific research }\end{array}$ & 16 & 53.3 & 14 & 46.7 & 0 & 0.0 & 0 & 0.0 & 0 & 0.0 \\
\hline 5-Restructuring is possible for the necessities & 16 & 53.3 & 13 & 43.3 & 1 & 3.3 & 0 & 0.0 & 0 & 0.0 \\
\hline \multicolumn{11}{|c|}{ D-General evaluation of the electronic records system: } \\
\hline 1-The generation of records is fast & 25 & 83.3 & 4 & 13.3 & 1 & 3.3 & 0 & 0.0 & 0 & 0.0 \\
\hline 2-The records are useful & 28 & 93.3 & 2 & 6.7 & 0 & 0.0 & 0 & 0.0 & 0 & 0.0 \\
\hline 3-The records present updated information & 26 & 86.7 & 2 & 6.7 & 1 & 3.3 & 1 & 3.3 & 0 & 0.0 \\
\hline 4-The records are easily configured & 24 & 80.0 & 3 & 10.0 & 2 & 6.7 & 1 & 3.3 & 0 & 0.0 \\
\hline $\begin{array}{l}\text { 5-The records of the system present an appropriate } \\
\text { format }\end{array}$ & 24 & 80.0 & 5 & 16.7 & 0 & 0.0 & 1 & 3.3 & 0 & 0.0 \\
\hline $\begin{array}{lllll}\text { 6-The records of the system present good } \\
\text { organization }\end{array}$ & 24 & 80.0 & 6 & 20.0 & 0 & 0.0 & 0 & 0.0 & 0 & 0.0 \\
\hline 7-The system has enough records for its activity & 16 & 53.3 & 12 & 40.0 & 2 & 6.7 & 0 & 0.0 & 0 & 0.0 \\
\hline
\end{tabular}

Employees evaluation of electronic records system usage: Regarding to general evaluation of system operation; Table (4): depicted that the majority of them completely agreed that it is easy to input information into electronic records, easy to use, and system works well $(\mathbf{9 0 \%}, \mathbf{8 6 . 7 \%}$, and $\mathbf{8 0 \%})$ respectively. While $\mathbf{( 7 6 . 7 \% )}$ of employees completely agreed that the system's speed is good and facilitates the implementation of internal protocol. Regarding to evaluation of information made available; high percent of them $\mathbf{( 8 3 . 3 \% )}$ completely agreed that the system provides clear information, and $\mathbf{( 8 0 \% )}$ completely agreed that it is divided in a consistent manner and provides useful information. And $\mathbf{( 7 0 \% )}$ completely agreed that it provides complete and reliable information. Concerning evaluation of screens of the system; the majority of them completely agreed that it is easy access to the records, disappearance of paper records, and the system has the ability to see \& analyze the patient data as a whole (86.7\%, 76.7\%, and73.3\%) respectively. For general evaluation of electronic records system; the vast majority of them completely agreed that the records are useful, present updated information, and the generation of records is fast $(\mathbf{9 3 . 3 \%}, \mathbf{8 6 . 7 \%}$, and $\mathbf{8 3 . 3 \% )}$ respectively. And $\mathbf{( 8 0 \% )}$ of employees completely agreed that the records are easily configured, present an appropriate format, and present good organization.

Table (5): Percentage distribution of physicians evaluation of the utility of electronic records system used in AL-Rajhy hospital $(\mathbf{n}=\mathbf{2 0})$

\begin{tabular}{|c|c|c|c|c|c|c|c|c|c|c|}
\hline \multirow[t]{2}{*}{ Items } & \multicolumn{2}{|c|}{$\begin{array}{l}\text { Completely } \\
\text { agree }\end{array}$} & \multicolumn{2}{|c|}{ Agree } & \multicolumn{2}{|c|}{ Indifferent } & \multicolumn{2}{|c|}{ Disagree } & \multicolumn{2}{|c|}{$\begin{array}{c}\text { Completely } \\
\text { disagree }\end{array}$} \\
\hline & No. & $\%$ & No. & $\%$ & No. & $\%$ & No. & $\%$ & No. & $\%$ \\
\hline \multicolumn{11}{|c|}{ A-Utility of electronic records: } \\
\hline 1-The records facilitate the decision process & 10 & $\mathbf{5 0 . 0}$ & 9 & 45.0 & 1 & 5.0 & 0 & 0.0 & 0 & 0.0 \\
\hline $\begin{array}{l}\text { 2-The records improve the reliability of decision } \\
\text { process }\end{array}$ & 9 & 45.0 & 10 & 50.0 & 1 & 5.0 & 0 & 0.0 & 0 & 0.0 \\
\hline $\begin{array}{l}\text { 3-The records increase the level of control over } \\
\text { operation }\end{array}$ & 10 & $\mathbf{5 0 . 0}$ & 10 & 50.0 & 0 & 0.0 & 0 & 0.0 & 0 & 0.0 \\
\hline 4-The records facilitate the coordination of tasks & 10 & 50.0 & 10 & 50.0 & 0 & 0.0 & 0 & 0.0 & 0 & 0.0 \\
\hline
\end{tabular}


Minia Scientific Nursing Journal (Print) (ISSN 2537-012X) Vol. (6) No. (1) December 2019

\begin{tabular}{|c|c|c|c|c|c|c|c|c|c|c|}
\hline \multirow[t]{2}{*}{ Items } & \multicolumn{2}{|c|}{$\begin{array}{l}\text { Completely } \\
\text { agree }\end{array}$} & \multicolumn{2}{|c|}{ Agree } & \multicolumn{2}{|c|}{ Indifferent } & \multicolumn{2}{|c|}{ Disagree } & \multicolumn{2}{|c|}{$\begin{array}{l}\text { Completely } \\
\text { disagree }\end{array}$} \\
\hline & No. & $\%$ & No. & $\%$ & No. & $\%$ & No. & $\%$ & No. & $\%$ \\
\hline 5-The records offer reliability & 9 & 45.0 & 11 & 55.0 & 0 & 0.0 & 0 & 0.0 & 0 & 0.0 \\
\hline $\begin{array}{l}\text { 6-The records reduce the need for control, } \\
\text { surveillance, and conferencing }\end{array}$ & 2 & 10.0 & 5 & 25.0 & 6 & 30.0 & 5 & 25.0 & 2 & 10.0 \\
\hline \multicolumn{11}{|c|}{ B-Utility of the electronic system for medical and nursing work: } \\
\hline $\begin{array}{l}\text { 1-Facilitates work in the sector of guidelines and } \\
\text { authorizations }\end{array}$ & 2 & 10.0 & 15 & 75.0 & 3 & 15.0 & 0 & 0.0 & 0 & 0.0 \\
\hline 2-Facilitates patient care & 3 & 15.0 & 14 & 70.0 & 3 & 15.0 & 0 & 0.0 & 0 & 0.0 \\
\hline $\begin{array}{l}\text { 3-Facilitates work in the medical evolution of } \\
\text { patients }\end{array}$ & 2 & 10.0 & 17 & 85.0 & 1 & 5.0 & 0 & 0.0 & 0 & 0.0 \\
\hline $\begin{array}{l}\text { 4-Facilitates nursing work in the evolution of } \\
\text { patients }\end{array}$ & 1 & 5.0 & 18 & 90.0 & 1 & 5.0 & 0 & 0.0 & 0 & 0.0 \\
\hline $\begin{array}{l}\text { 5-Facilitates work in the medical prescriptions for } \\
\text { patients }\end{array}$ & 9 & 45.0 & 11 & 55.0 & 0 & 0.0 & 0 & 0.0 & 0 & 0.0 \\
\hline $\begin{array}{l}\text { 6-Allows medications to be directly requested from } \\
\text { pharmacies }\end{array}$ & 15 & 75.0 & 5 & 25.0 & 0 & 0.0 & 0 & 0.0 & 0 & 0.0 \\
\hline \begin{tabular}{lllll|} 
7-Facilitates & nursing & work & and & checking \\
prescriptions
\end{tabular} & 13 & 65.0 & 7 & 35.0 & 0 & 0.0 & 0 & 0.0 & 0 & 0.0 \\
\hline $\begin{array}{l}\text { 8-Presents a good level of integration with the units } \\
\text { responsible for ASDT }{ }^{\circledR}\end{array}$ & 7 & 35.0 & 13 & 65.0 & 0 & 0.0 & 0 & 0.0 & 0 & 0.0 \\
\hline \multicolumn{11}{|c|}{ C-Utility of the electronic system for the processes of billing and auditing: } \\
\hline 1-Facilitates hospital billing & 8 & 40.0 & 12 & 60.0 & 0 & 0.0 & 0 & 0.0 & 0 & 0.0 \\
\hline 2-Facilitates analysis of hospital bills & 8 & 40.0 & 12 & 60.0 & 0 & 0.0 & 0 & 0.0 & 0 & 0.0 \\
\hline 3-Reduces the occurrence of frauds & 6 & 30.0 & 5 & 25.0 & 8 & 40.0 & 0 & 0.0 & 1 & 5.0 \\
\hline $\begin{array}{l}\text { 4-Facilitates auditing in the authorization and } \\
\text { release of procedures }\end{array}$ & 6 & 30.0 & 14 & 70.0 & 0 & 0.0 & 0 & 0.0 & 0 & 0.0 \\
\hline $\begin{array}{l}\text { 5-Facilitates verification of the materials and } \\
\text { medications used in the units }\end{array}$ & 8 & 40.0 & 12 & 60.0 & 0 & 0.0 & 0 & 0.0 & 0 & 0.0 \\
\hline $\begin{array}{l}\text { 6-Provides better control over the consumption of } \\
\text { medications }\end{array}$ & 7 & 35.0 & 12 & 60.0 & 1 & 5.0 & 0 & 0.0 & 0 & 0.0 \\
\hline
\end{tabular}

General utility of electronic records system as evaluated by physicians; Regarding 3 dimensions of utility of electronic system, utility of electronic system for medical \& nursing work and utility of electronic system for the process of billing and auditing; Table (5) demonstrated that; more than half of them $\mathbf{5 5 \%}$ ) agreed that the records offer reliability, and about half of them completely agreed that it facilitate coordination of tasks, increase level of control over operation and facilitates the decision process. While the majority of them agreed that the electronic records facilitate nursing work in the evolution of the patient, facilitate work in the medical evolution of patient, and facilitate work in the sector of guidelines \& authorization $(\mathbf{9 0 \%}, \mathbf{8 5 \%}$, and $\mathbf{7 5 \%} \%$ respectively. Also; $\mathbf{( 7 0} \%)$ of them agreed that the records facilitate auditing and release of procedures, $(\mathbf{6 0 \%})$ agreed that it facilitates analysis of hospital bills, facilitates verification of the materials \& medications used in units, facilitates hospital billing, and provides better control over the consumption of medications.

Table (6): Percentage distribution of nurses evaluation of the utility of electronic records system used in AL-Rajhy hospital $(\mathbf{n}=\mathbf{2 0 0})$

\begin{tabular}{|c|c|c|c|c|c|c|c|c|c|c|}
\hline \multirow[t]{2}{*}{ Items } & \multicolumn{2}{|c|}{$\begin{array}{l}\text { Completely } \\
\text { agree }\end{array}$} & \multicolumn{2}{|c|}{ Agree } & \multicolumn{2}{|c|}{ Indifferent } & \multicolumn{2}{|c|}{ Disagree } & \multicolumn{2}{|c|}{$\begin{array}{c}\text { Completely } \\
\text { disagree }\end{array}$} \\
\hline & No. & $\%$ & No. & $\%$ & No. & $\%$ & No. & $\%$ & No. & $\%$ \\
\hline \multicolumn{11}{|c|}{ A-Utility of electronic records: } \\
\hline 1-The records facilitate the decision process & 63 & 31.5 & 121 & 60.5 & 15 & 7.5 & 1 & 0.5 & 0 & 0.0 \\
\hline 2-The records improve the reliability of decision process & 61 & 30.5 & 116 & $\mathbf{5 8 . 0}$ & 21 & 10.5 & 2 & 1.0 & 0 & 0.0 \\
\hline 3-The records increase the level of control over operation & 59 & 29.5 & 113 & 56.5 & 27 & 13.5 & 1 & 0.5 & 0 & 0.0 \\
\hline 4-The records facilitate the coordination of tasks & 60 & 30.0 & 128 & 64.0 & 11 & 5.5 & 1 & 0.5 & 0 & 0.0 \\
\hline 5-The records offer reliability & 65 & 32.5 & 115 & $\mathbf{5 7 . 5}$ & 18 & 9.0 & 2 & 1.0 & 0 & 0.0 \\
\hline $\begin{array}{l}\text { 6-The records reduce the need for control, surveillance, } \\
\text { and conferencing }\end{array}$ & 36 & 18.0 & 85 & 42.5 & 43 & 21.5 & 35 & 17.5 & 1 & 0.5 \\
\hline \multicolumn{11}{|c|}{ B-Utility of the electronic system for medical and nursing work: } \\
\hline $\begin{array}{l}\text { 1-Facilitates work in the sector of guidelines and } \\
\text { authorizations }\end{array}$ & 74 & 37.0 & 102 & 51.0 & 20 & 10.0 & 4 & 2.0 & 0 & 0.0 \\
\hline 2-Facilitates patient care & 64 & 32.0 & 119 & 59.5 & 15 & 7.5 & 2 & 1.0 & 0 & 0.0 \\
\hline 3-Facilitates work in the medical evolution of patients & 50 & 25.0 & 99 & 49.5 & 48 & 24.0 & 3 & 1.5 & 0 & 0.0 \\
\hline 4-Facilitates nursing work in the evolution of patients & 55 & 27.5 & 111 & 55.5 & 32 & 16.0 & 2 & 1.0 & 0 & 0.0 \\
\hline 5-Facilitates work in the medical prescriptions for patients & 85 & 42.5 & 108 & 54.0 & 3 & 1.5 & 4 & 2.0 & 0 & 0.0 \\
\hline $\begin{array}{l}\begin{array}{l}\text { 6-Allows medications to be directly requested from } \\
\text { pharmacies }\end{array} \\
\end{array}$ & 115 & 57.5 & 84 & 42.0 & 1 & 0.5 & 0 & 0.0 & 0 & 0.0 \\
\hline 7-Facilitates nursing work and checking prescriptions & 116 & 58.0 & 78 & 39.0 & 4 & 2.0 & 2 & 1.0 & 0 & 0.0 \\
\hline $\begin{array}{l}\text { 8-Presents a good level of integration with the units } \\
\text { responsible for ASDT } ®\end{array}$ & 77 & 38.5 & 112 & 56.0 & 10 & 5.0 & 1 & 0.5 & 0 & 0.0 \\
\hline \multicolumn{11}{|c|}{ C-Utility of the electronic system for the processes of billing and auditing: } \\
\hline 1-Facilitates hospital billing & 102 & 51.0 & 92 & 46.0 & 5 & 2.5 & 1 & 0.5 & 0 & 0.0 \\
\hline 2-Facilitates analysis of hospital bills & 95 & 47.5 & 101 & 50.5 & 4 & 2.0 & 0 & 0.0 & 0 & 0.0 \\
\hline 3-Reduces the occurrence of frauds & 72 & 36.0 & 77 & 38.5 & 30 & 15.0 & 21 & 10.5 & 0 & 0.0 \\
\hline $\begin{array}{l}\text { 4-Facilitates auditing in the authorization and release of } \\
\text { procedures }\end{array}$ & 70 & 35.0 & 121 & 60.5 & 9 & 4.5 & 0 & 0.0 & 0 & 0.0 \\
\hline 5-Facilitates verification of the materials and medications & 87 & 43.5 & 109 & 54.5 & 3 & 1.5 & 1 & 0.5 & 0 & 0.0 \\
\hline
\end{tabular}




\begin{tabular}{|c|c|c|c|c|c|c|c|c|c|c|}
\hline \multirow[t]{2}{*}{ Items } & \multicolumn{2}{|c|}{$\begin{array}{l}\text { Completely } \\
\text { agree }\end{array}$} & \multicolumn{2}{|c|}{ Agree } & \multicolumn{2}{|c|}{ Indifferent } & \multicolumn{2}{|c|}{ Disagree } & \multicolumn{2}{|c|}{$\begin{array}{c}\text { Completely } \\
\text { disagree }\end{array}$} \\
\hline & No. & $\%$ & No. & $\%$ & No. & $\%$ & No. & $\%$ & No. & $\%$ \\
\hline used in the units & & & & & & & & & & \\
\hline $\begin{array}{l}\text { 6-Provides better control over the consumption of } \\
\text { medications }\end{array}$ & 82 & 41.0 & 108 & 54.0 & 9 & 4.5 & 1 & 0.5 & 0 & 0.0 \\
\hline
\end{tabular}

General utility of electronic records system as evaluated by nurses; Table (6) described that more than two third of them agreed that it facilitate the coordination of tasks, decision process and improve the reliability of decision process $(\mathbf{6 4 \%}, \mathbf{6 0 . 5 \%}$, and $\mathbf{5 6} \%$ ) respectively. While about $(\mathbf{4 2}, \mathbf{5 \%})$ of them agreed that the records reduce the need for control, surveillance and conferencing. Regarding utility of electronic system for nursing work; it was shown that more than half of them $\mathbf{( 5 9 . 5 \% , ~ a n d ~} \mathbf{5 6 \%}$ ) agreed that it facilitate patient care, and presents a good level of integration with the other units. Also (55.5\% and $\mathbf{5 4 \% )}$ agreed that it facilitate nursing work in the evolution of patients, and facilitates work in the medical prescriptions for patients. Similarly; about two third of them $\mathbf{( 6 0 . 5 \% )}$ ) agreed that it facilitates auditing in the authorization and release of procedures, and more than half of them agreed that it facilitate verification of materials and medications used in the units and provides better control over the consumption of medications $(\mathbf{5 4 . 5 \%}$, and $\mathbf{5 4 \%}$ ) respectively.

Table (7): Percentage distribution of employees evaluation of the utility of electronic records system used in AL-Rajhy hospital $(\mathbf{n}=\mathbf{3 0})$

\begin{tabular}{|c|c|c|c|c|c|c|c|c|c|c|}
\hline \multirow{2}{*}{ Items } & \multicolumn{2}{|c|}{$\begin{array}{c}\text { Completely } \\
\text { agree }\end{array}$} & \multicolumn{2}{|c|}{ Agree } & \multicolumn{2}{|c|}{ Indifferent } & \multicolumn{2}{|c|}{ Disagree } & \multicolumn{2}{|c|}{$\begin{array}{c}\text { Completely } \\
\text { disagree }\end{array}$} \\
\hline & No. & $\%$ & No. & $\%$ & No. & $\%$ & No. & $\%$ & No. & $\%$ \\
\hline \multicolumn{11}{|c|}{ A-Utility of electronic records: } \\
\hline 1-The records facilitate the decision process & 20 & 66.7 & 9 & 30.0 & 1 & 3.3 & 0 & 0.0 & 0 & 0.0 \\
\hline $\begin{array}{l}\text { 2-The records improve the reliability of decision } \\
\text { process }\end{array}$ & 17 & 56.7 & 12 & 40.0 & 1 & 3.3 & 0 & 0.0 & 0 & 0.0 \\
\hline $\begin{array}{l}\text { 3-The records increase the level of control over } \\
\text { operation }\end{array}$ & 20 & 66.7 & 10 & 33.3 & 0 & 0.0 & 0 & 0.0 & 0 & 0.0 \\
\hline 4-The records facilitate the coordination of tasks & 20 & 66.7 & 10 & 33.3 & 0 & 0.0 & 0 & 0.0 & 0 & 0.0 \\
\hline 5-The records offer reliability & 20 & 66.7 & 9 & 30.0 & 1 & 3.3 & 0 & 0.0 & 0 & 0.0 \\
\hline $\begin{array}{|lcccc|}\text { 6-The records reduce the need for control, } \\
\text { surveillance, and conferencing }\end{array}$ & 18 & 60.0 & 10 & 33.3 & 0 & 0.0 & 2 & 6.7 & 0 & 0.0 \\
\hline \multicolumn{11}{|c|}{ B-Utility of the electronic system for medical and nursing work: } \\
\hline $\begin{array}{l}\text { 1-Facilitates work in the sector of guidelines and } \\
\text { authorizations }\end{array}$ & 21 & 70.0 & 7 & 23.3 & 2 & 6.7 & 0 & 0.0 & 0 & 0.0 \\
\hline 2-Facilitates patient care & 7 & 23.3 & 18 & 60.0 & 5 & 16.7 & 0 & 0.0 & 0 & 0.0 \\
\hline $\begin{array}{l}\text { 3-Facilitates work in the medical evolution of } \\
\text { patients }\end{array}$ & 3 & 10.3 & 17 & 58.6 & 9 & 31.0 & 0 & 0.0 & 0 & 0.0 \\
\hline $\begin{array}{l}\text { 4-Facilitates nursing work in the evolution of } \\
\text { patients }\end{array}$ & 3 & 10.0 & 17 & 56.7 & 10 & 33.3 & 0 & 0.0 & 0 & 0.0 \\
\hline $\begin{array}{l}\text { 5-Facilitates work in the medical prescriptions for } \\
\text { patients }\end{array}$ & 7 & 23.3 & 22 & 73.3 & 1 & 3.3 & 0 & 0.0 & 0 & 0.0 \\
\hline $\begin{array}{l}\text { 6-Allows medications to be directly requested from } \\
\text { pharmacies }\end{array}$ & 16 & 53.3 & 14 & 46.7 & 0 & 0.0 & 0 & 0.0 & 0 & 0.0 \\
\hline $\begin{array}{lllll}\text { 7-Facilitates nursing } & \text { work } & \text { and } & \text { checking } \\
\text { prescriptions }\end{array}$ & 14 & 46.7 & 15 & 50.0 & 1 & 3.3 & 0 & 0.0 & 0 & 0.0 \\
\hline $\begin{array}{l}\text { 8-Presents a good level of integration with the units } \\
\text { responsible for ASDT } \AA\end{array}$ & 10 & 33.3 & 20 & 66.7 & 0 & 0.0 & 0 & 0.0 & 0 & 0.0 \\
\hline \multicolumn{11}{|c|}{ C-Utility of the electronic system for the processes of billing and auditing: } \\
\hline 1-Facilitates hospital billing & 26 & 86.7 & 4 & 13.3 & 0 & 0.0 & 0 & 0.0 & 0 & 0.0 \\
\hline 2-Facilitates analysis of hospital bills & 25 & 83.3 & 5 & 16.7 & 0 & 0.0 & 0 & 0.0 & 0 & 0.0 \\
\hline 3-Reduces the occurrence of frauds & 25 & 83.3 & 5 & 16.7 & 0 & 0.0 & 0 & 0.0 & 0 & 0.0 \\
\hline $\begin{array}{l}\text { 4-Facilitates auditing in the authorization and } \\
\text { release of procedures }\end{array}$ & 23 & 76.7 & 7 & 23.3 & 0 & 0.0 & 0 & 0.0 & 0 & 0.0 \\
\hline $\begin{array}{l}\text { 5-Facilitates verification of the materials and } \\
\text { medications used in the units }\end{array}$ & 22 & 73.3 & 8 & 26.7 & 0 & 0.0 & 0 & 0.0 & 0 & 0.0 \\
\hline $\begin{array}{l}\text { 6-Provides better control over the consumption of } \\
\text { medications }\end{array}$ & 20 & 66.7 & 10 & 33.3 & 0 & 0.0 & 0 & 0.0 & 0 & 0.0 \\
\hline
\end{tabular}

General utility of electronic records system as evaluated by employees; Table (7), described employees opinion regarding utility of electronic records system; it showed that more than two thirds of them (66.7\%) completely agreed that it facilitate decision process, offer reliability, increase level of control over operation, and(60\%) agreed that it reduce the need for control, surveillance and conferencing. For utility of electronic health records for medical and nursing work; more than two third of employees agreed that it facilitates work in medical prescription for patients, presents a good level of integration with the other units, and facilitates patients care. As regarding to utility of electronic system for the process of billing and auditing; the majority of them $(\mathbf{8 6 . 7 \%}$, and $\mathbf{8 3 . 3 \% )}$ completely agreed that it facilitates hospital billing, reduce the occurrence of frauds, and facilitates analysis of hospital bills .while $\mathbf{( 7 6 . 7 \%}$, and $\mathbf{7 3 . 3 \%}$ ) completely agreed that it facilitates auditing in the authorization \& release of procedures and facilitates verification of the materials \& medications used in the units.

Table (8): Mean scores of evaluation of electronic records system and general utility of electronic records system by study subjects $(\mathbf{n}=\mathbf{2 5 0})$ at AL-Rajhy hospital 
Minia Scientific Nursing Journal (Print) (ISSN 2537-012X) Vol. (6) No. (1) December 2019

\begin{tabular}{|c|c|c|c|c|}
\hline \multirow[t]{2}{*}{ Items } & Physicians & Nurses & Employees & \multirow{2}{*}{$\begin{array}{c}\text { P- } \\
\text { Value }\end{array}$} \\
\hline & Mean \pm SD & Mean \pm SD & Mean \pm SD & \\
\hline \multicolumn{5}{|l|}{ A- Evaluation of electronic records system: } \\
\hline 1-General evaluation of electronic system operation & $28.45 \pm 1.64$ & $25.21 \pm 3.18$ & $28.50 \pm 2.50$ & $0.000 *$ \\
\hline 2-Evaluation of the information made available & $23.70 \pm 1.84$ & $20.88 \pm 3.02$ & $23.50 \pm 2.65$ & $0.000 *$ \\
\hline 3-Evaluation of the screens of the system & $23.10 \pm 1.71$ & $21.04 \pm 2.40$ & $23.37 \pm 1.79$ & $0.000 *$ \\
\hline 4-General evaluation of the electronic records system & $33.75 \pm 2.53$ & $31.26 \pm 3.47$ & $33.17 \pm 2.84$ & 0.001* \\
\hline \multicolumn{5}{|l|}{ B- General utility of electronic records system: } \\
\hline 1-Utility of electronic records & $25.30 \pm 3.21$ & $24.61 \pm 3.34$ & $27.60 \pm 2.92$ & $0.000 *$ \\
\hline 2-Utility of the electronic system for medical and nursing work & $34.20 \pm 2.75$ & $34.33 \pm 4.05$ & $33.66 \pm 3.04$ & 0.819 \\
\hline $\begin{array}{l}\text { 3-Utility of the electronic system for the processes of billing and } \\
\text { auditing }\end{array}$ & $25.55 \pm 3.12$ & $26.00 \pm 2.97$ & $28.70 \pm 2.15$ & $0.000 *$ \\
\hline
\end{tabular}

Table (8) demonstrated the mean scores of evaluation of electronic records system and general utility of electronic records system. There were high statistical significant difference among (physicians, nurses, and employees) regarding general evaluation of electronic system and utility of the electronic system $(\mathbf{p}=\mathbf{0 . 0 0 0 *})$.

\section{Discussion}

Information Systems defined as "A combination of hardware, software, infrastructure and trained personnel organized to facilitate planning, control, coordination, and decision making in an organization (Ouma \& Marlien et al., 2009).

To fully utilize of EHRs, adoption more efficient technologies to provide better services for patients, where investment in information technology is prepared to address financial, medical, and marketing issues, to improve service quality, increase patient satisfaction, to make more legible and accessible patient records, to improve response time, and to meet the pressure from patients. Thus information technology (IT) can improve both aspects- medical care and administrative structure through help the administrators to have better monitoring and control of the functioning of hospitals using decision support indicators. (Moghaddasi et al., 2013)

Adoption of Information technology in health area across developing countries accelerates knowledge diffusion, increase access to health information, essential to reform healthcare and meet patients' needs. IT for the health care field improves the effectiveness of provided care, enhancing patient safety, increase workforce productivity and satisfaction. Developing countries are now has awareness that there is a need to embrace information and communication technologies to cope with the problem of access, quality and costs of healthcare (Ojo et al., 2015).

The present study was conducted with the aim of evaluation the effectiveness of using electronic health information system at AL-Rajhy Assuit University for Liver.

Regarding to general evaluation of electronic health records operation as perceived by physicians; the majority of physicians agreed that the system works well, speed is good, and easy to input information into electronic records, the records easy to use. Regarding to evaluation of information made available, most of them agreed that the system provides clear, useful, complete, and reliable information. Regarding to evaluation of the screens of the system, the highest present of them agreed that the screens has the ability to retrieve faster and reliable data for specific research, has the ability to see $\&$ analyze the patient data as a whole and easy access to the records . For general evaluation of electronic records system, most of physicians agreed that the records are useful, present updated information in an appropriate format, and are easily configured.

This finding consistent with Van Valkenhoef et al., (2013) stated that the electronic record system easy to use and display needed data, to analyze them, to share them among colleagues, improves the convenience of storage and ease of retrieval of a patient's records.Thus, a doctor can recommend or manage proper treatment according to clinical guidelines, with a lower risk of adverse implications on patient's health.

Also, this finding was supported by Jha, et al., (2018) whose reported that; EHRs enabled easy access to medical records, improved speed and ease of retrieval of records, paths to flag abnormal results and elimination of handwritten prescriptions which reduces the occurrence of prescription errors.

While it was disagreed with Pagliari et al., (2017) who noted that, one of the main reasons for Electronic patient Record (EPR) implementation failure is due to the complexity of the healthcare services, so the personal health records of the individuals with health services become complex.

Regarding to evaluation of electronic records system used in Al-Rajhy hospital by nurses; the majority of them agreed that the system easy to use, works well, and easy to input information into electronic records. And most of them agreed that the system provides clear, useful information, divided in a consistent manner, has the ability to retrieve faster and reliable data for scientific research, restricting is possible for the necessities and has the ability to see $\&$ analyze the patient data as a whole, the generation of records is fast, records present updated and useful information.

With this respect Rotich et al., (2003) stated that the EHRs were faster and much easier, provide complete, useful information compared to the use of paper based records and this helped save a lot of time to concentrate on the provision of 'real' physical care to the patient, and coded data for statistical \& research purposes.

This was in line with Bundschuh., (2011) who had asserted that, EMRs, when used correctly, is a tool that can increase quality of patient care by providing the nurse with an easier, complete, efficient, timely, and safe medical record.

This is congruent with Ceylan, (2012) who explored that EHRs enable each individual to obtain current and accurate information about health. Also, individuals can easily access their own health information into EHR.

For evaluation of electronic records system used in Al-Rajhy hospital as perceived by employees; the majority of them agreed that it is easy to input information into electronic records, it is easy to use, system works well, the system's speed is good it is easy access to the records, disappearance of paper records, the system has the ability to see $\&$ analyze the patient data as a whole, the records are useful, present updated information, and the generation of records is fast. And; high percent of them agreed that the system provides clear 
information, it is divided in a consistent manner and it provides useful information.

This in agreement with the study done by Rotich et al., (2003) who stated that the users found the EHRs faster and much easier to use than the paper based recording system and this enabled users to see \& analyze patient's data in a much shorter time than before. Also, the clerks spent less time writing reports and interacting with other staff.

Ammenwerth et al., (2005) added that, as with manual systems, the accuracy of electronically recorded data is also a concern for healthcare administrators and professionals. And the electronic health records are more accurate and readily available than manual records.

On the other hand Ludwick \& Doucette., (2009) revealed that, the use of electronic record systems helps to minimize duplication of inputs, thereby improving the accuracy of patients' data by comparison to non-electronic processes.

Likewise Blaya et al., (2010) found that, using electronic coding to identify, centralize and store all data categories into each patient record; various practitioners can easily retrieve, use and update a single file without duplicating the patient record.

General utility of electronic records system as perceived by physicians; the majority of them agreed that the records offer reliability, facilitates coordination of tasks, increase level of control over operation and facilitates decision process. While most of them agreed that the electronic records facilitate nursing work in the evolution of the patient, facilitate work in the medical evolution of patient, and facilitate work in the sector of guidelines \& authorization. Also; high percent of them agreed that the records facilitate auditing and release of procedures, facilitate analysis of hospital bills, facilitate verification of the materials \& medications used in units, facilitates hospital billing, and provides better control over the consumption of medications.

According to Kumar, (2011), information from a patient's record is critical in making health-related decisions and timely access to this information in healthcare facilities is principal to achieving efficient care delivery.

With this respect in study finding of Lin, Lin \& Roan, (2012) emphasized that, the implemented primarily used by clinical staff are patient-centric and directly enable them to quickly make decisions on treatment. The system is also an essential utility for data management on a daily basis such that it improves their work processes and work in the medical evolution of patient.

This was in line with a study finding of Alpert., (2016) who showed that, with use EHRs, clinicians can more easily coordinate and facilitate patient care across practices; also collaborate on patient outcomes as a team to ensure better care overall.

With this respect in study finding of Lin, Lin \& Roan, (2012) emphasized that, the implemented primarily used of EHRs by clinical staff are patient-centric and directly enable them to quickly make decisions on treatment. The system is also an essential utility for data management on a daily basis such that it improves their work processes and work in the medical evolution of patient.

This was in line with study finding of Alpert, (2016) who showed that, with use EHRs, clinicians can more easily coordinate and facilitate patient care across practices; also collaborate on patient outcomes as a team to ensure better care overall.
While inconsistent with study finding of Gittell \&Weiss, (2004) pointed to the problems of coordination and communication, both within hospitals and with outside agencies. By way of patient care represents a particular challenge, as its delivery is often highly fragmented, with diagnosis and treatment being supplied by a diverse group of loosely coupled service providers on a single site.

General utility of electronic records system as perceived by nurses; high percent of them agreed that it facilitate the coordination of tasks, decision process, improve the reliability of decision process, facilitate continuity of patient care, and presents a good level of integration with the other units. Also more than half of nurses agreed that it facilitate nursing work in the evolution of patients, facilitates work in the medical prescriptions for patients, facilitate verification of materials \& medications used in the units and provides better control over the consumption of medications .

This finding in accordance with study finding of Locsin, ( 2005) who found that computerized data can provide quick and easy access to patient data and provide information in a comprehensive, integrated fashion; analysis of patient care outcomes is facilitated and better reporting of data and patient care outcomes can be accomplished.

Moreover, Malliarou et al., (2007) added that the activities that nurses perform when caring for patients as coordinating activities that involve the gathering and transmission of patient information, order entry, results reporting, requisition generation, and telephone booking of appointments. The current systems can capture these tasks from the physicians' order entry set and then incorporate them into the patient care plan then communication and cooperation with other health professionals improved. This continuity of care is very important in providing qualitative health services.

Also this finding consistent with study finding of Black, et al., (2011) who said that The EHRs have different advantages over paper records include; the opportunity for healthcare organizations to improve the quality of patient care and safety, facilitate nursing work in the evolution of patients and improve efficiency of the workplace.

While according to Chiang, et al., (2013) the traditional paper-based approach to clinical documentation has become overwhelmed by information exchange demands among health care providers, financial and legal complexities of the modern health care environment, the increasing rate of biomedical knowledge, growing chronic care needs from an aging population, and medical errors associated with handwritten notes.

Regarding to general utility of electronic records system as illustrated by employees; the majority of them agreed that it facilitate decision process, offer reliability, increase level of control over operation, facilitates work in medical prescription for patients, presents a good level of integration with the other units, and facilitates patients care. And most of them agreed that it facilitates hospital billing, reduce the occurrence of frauds, and facilitates analysis of hospital bills.

Also Medical Record Consultants, (2007) identified that implementation of EHR streamlined financial collection, minimized workload, patient visits, writing, space for records, manpower and cost. EHR system used as tools to support administrative procedures, such as billing and scheduling, also facilitate clinical decision-making and minimize the potential for mistakes due to the inaccuracy and incompleteness of paper records. 
According to Ghosh, (2010) Hospital information systems help to improve operational efficiency, care quality and more informed decision making, give comfortable and quick access to patient data.

Moreover, Fichman, et al., (2011) mentioned that information systems in healthcare allow the capture and dissemination of information to decision makers for better coordination of healthcare at both the individual and population levels.

While Alpert., (2016) added that the electronic records system make it possible for the services a patient needs as ; office visits, testing, surgery, hospital visits to be coordinated and scheduled over the course of a single visit rather than time-consuming multiple visits.

\section{Conclusion}

In the light of the study results, the following conclusions can be drawn:

- The total percent of the studied groups (100\%) are already using EHRs and most of them are using the systems in all or most of their job tasks.

- There were high statistical significant difference among physicians, nurses, and employees $(\mathbf{p}=\mathbf{0 . 0 0 0 *})$ as regards to general evaluation of electronic system operation, evaluation of the information made available and evaluation of the electronic records system.

- There were statistical significant differences among physicians, nurses, and employees $(\mathbf{p}=\mathbf{0 . 0 1 1}$ ) $)$ and utility of electronic records, utility of the electronic system for the processes of billing and auditing $(\mathbf{p}=0.000 *)$.

\section{Recommendations}

- Use online assistance as possible; to provide the users with the possibility of revising of the errors and wrong information, the system should be easily reversible and flexible in the shortest time.

- Support IT department personnel should constantly be available to the users so that losing the data is minimized.

- Pay attention from designers of a system of adding new features to the system with regard to meeting new needs in future.

- Arrange awareness symposium for e-HISs users regarding the benefits of IT and e-HIS.

- Arrange continuous training workshops for e-HISs users to improve their computer and e-HIS proficiency and skills.

- Provide the personnel who are competent in computer and IS instructors the chance to make awareness, training and education of employees and care providers.

- Motivate e-HISs users to participate in process designing as they will be the future users of the new system.

- Motivate the e-HISs users to accept new system by communicating a clear vision of new system among them.

- Considers user's requirements and needs for improvement mechanisms.

- Assured user's satisfaction while designing process for new system.

$P$ a g e | 116
- Formulate/ prepare a manual in every unit discussing how to use e-HIS as a reference for all employees working in the health care settings.

\section{Reference}

1) Aghazadeh,S., Aliyev, A., Ebrahimnezhad, M. (2013): Study the effect of Hospital Information Systems (HIS) on Communication Improvement and Service Quality among Nursing Staff, Life Science Journal, 10(s), 307-310.

2) Alpert, J. (2016): "The electronic medical record in 2016: Advantages and disadvantages. Digit Med; 2:48-51."

3) Ammenwerth, E., Brender, J., Nykänen, P., Prokosch, H., Rigby, M. and Talmon, J. (2005): Visions and strategies to improve evaluation of health information systems. Reflections and lessons based on the HIS-EVAL workshop in Innsbruck.International Journal of Medical Informatics, 73(6), pp.479-491.

4) Black, A., et al. (2011): "The Impact of eHealth on the Quality and Safety of Health Care: A Systematic Overview. PLoS Med.; 8:e1000387."

5) Blaya, J. a, Fraser, H.S.F. \& Holt, B. (2010): Ehealth technologies show promise in developing countries. Health affairs (Project Hope), 29(2): 24451.

6) Bundschuh BB, Majeed RW, Bürkle T, Kuhn K, Sax U, et al. (2011): Quality of human-computer interaction-results of a national usability survey of hospital-IT in Germany. BMC medical informatics and decision making 11: 69 .

7) Ceylan, F. (2012): Hastane Bilgi Yönetim Sistemleri Ders Notları, Uludağ Üniversitesi, Sağlık Hizmetleri Meslek Yüksekokulu, and Bursa.

8) Chiang, M. F., et al (2013): "Evaluation of Electronic Health Record Implementation in Ophthalmology at an Academic Medical Center (An American Ophthalmological Society Thesis)." Transactions of the American Ophthalmological Society 111: 70-92.

9) Coffman, J., K. Grumbach, M. Fix, L. Traister, and A. Bindman (2012): On the Road to Meaningful Use of EHRs: A Survey of California Physicians. Oakland, CA: California HealthCare Foundation

10) Cohen, J. F., E. Coleman, et al., (2016): An importance-performance analysis of hospital information system attributes: A nurses' perspective. International journal of medical informatics 86,82 90.

11) Côrtes, P.L. (2008): Administração de Sistemas de Informação. São Paulo: Saraiva.

12) Fichman, G. et al (2011): Editorial Overview - The role of IS in Healthcare Information Systems Research, Vol. 22: p.421.

13) Ghosh.N (2010): Benefits of Hospital Information System.

14) Gittell, J. H. \& Weiss, L. (2004): Coordination networks within and across organizations: A multilevel Framework. Journal of Management Studies, 41(1), 127-153.

15) http://www.ncbi.nlm.nih.gov/pubmed/20348068 22 March 2014. 
16) Jha, A. K., Burke, M. F., Desroches, C., Joshi, M. S., Kralovec, P. D., Campbell, E. G., \& Buntin, M. B. (2018) :Progress Toward Meaningful Use: Hospitals 'Adoption of Electronic Health Records. The American Journal of Managed Care, 17(2011), $1-6$.

17) Khalifa, M. (2014): Technical and human challenges of implementing hospital information systems in Saudi Arabia.Journal of Health Informatics in Developing Countries, 8(1), 298-343.

18) Kumar, V. (2011): "Impact of Health Information Systems on Organizational Health Communication and Behavior: The Internet Journal of Allied Health Sciences and Practice. 2011 Apr 01; 9(2), Article 8."

19) Lin, C., Lin, I.C. \& Roan, J. (2012): Barriers to physicians' adoption of healthcare information technology: An empirical study on multiple hospitals. Journal of Medical Systems, 36 (3).

20) Locsin, R. C. (2005): Technological competency as caring in nursing: A model for practice. Indianapolis: Sigma Theta Tau International.

21) Ludwick, D.A. \& Doucette, J. (2009): Adopting electronic medical records in primary care: lessons learned from health information systems implementation experience in seven countries. International journal of medical informatics, 78(1): 22-31.

http://www.ncbi.nlm.nih.gov/pubmed/18644745 20 March 2014.

22) Malliarou, M., Liaskos, J. \& Mantas, J. (2007): Legislative issues in the processing of sensitive personal data in the electronic patient record. Conference Proceedings of 5th ICICTH International Conference on Information Communication Technologies in Health; Samos: Greece; pp. 133-141

23) Medical Record Consultants (2007): Role in Implementing Electronic Health Record". Published in Proceedings of 15th International Health Record Congress, held at Seoul, South Korea, 26-31 May, 2007

24) Middleton, B., Bloomrosen, M., Dente, M. a, Hashmat, B., Koppel, R.,Overhage, J.M., Payne,
T.H., Rosenbloom, S.T., Weaver, C. \& Zhang, J. (2013

25) Moghaddasi H, Asadi F, Hossaini A, Mohammadpour A (2013): Hospital information system in Iran: findings from a systematic review. Hakim Research Journal; 16(3):228-35. [Google Scholar]

26) Ojo, A. I. and S. O. Popoola (2015): "Some Correlates of Electronic Health Information Management System Success in Nigerian Teaching Hospitals." Biomedical Informatics Insights 7: 1-9.

27) Pagliari, C., Detmer, D. and Singleton, P. (2017): "Potential of electronic personal health records", British medical journal (BMJ), 335(7615) p.p. 330333

28) Rose D, Richter LT, Kapustin J, (2014): Patient experiences with electronic medical records: lessons learned. J Am Assoc Nurse Pract. 2014; 26(12):674680.

29) Rotich JK, Hannan JK, Smith FE, Bii J, Odero WW, Vu N, Mamlin BW, Mamlin JJ et al (2003): Installing and implementing a computer-based patient record system in sub Saharan Africa: The Mosoriot Medical Record System. JAMIA 2003 Jul/Aug 110(4):295-303.

30) Shortliffe, E. H., \& Barnett, G. O. (2014): Biomedical data: Their acquisition, storage, and use.In Biomedical informatics (pp. 39-66).

31) Stella Ouma, Marlien E. Herselman and Van Greunen (2009): Implementing Successful E-health Implementations within Developing Countries

32) U.S. Department of Health and Human Services (2014): Benefits of EHRs. Improved Care Coordination. HealthIT.gov, from http://www.healthit.gov/providersprofessionals/improved-care-coordination

33) Van Valkenhoef, G., Tervonen, T., Zwinkels, T., De Brock, B. \& Hillege, H. (2013); ADDIS: A decision support system for evidence-based medicine. Decision Support Systems, 55(2): 459-475 